\title{
Age Related Changes in the Histoarchitecture of Seminiferous Epithelium in Mice
}

\section{R. Kaavya ${ }^{1}$, T.A.Kannan ${ }^{2 *}$, Sabiha Hayath Basha, S.Vairamuthu ${ }^{3}$, Geetha Ramesh $^{1}$ and B. Justin William ${ }^{2}$}

\author{
${ }^{1}$ Department of Veterinary Anatomy, Madras Veterinary College, Tamil Nadu Veterinary and \\ Animal Sciences University, Chennai- 600 007, India \\ ${ }^{2}$ Centre for Stem Cell Research and Regenerative Medicine, Madras Veterinary College, Tamil \\ Nadu Veterinary and Animal Sciences University, Chennai- 600 007, India \\ ${ }^{3}$ Central Clinical Laboratory, Madras Veterinary College, Tamil Nadu Veterinary and Animal \\ Sciences University, Chennai- 600 007, India \\ *Corresponding author
}

\section{A B S T R A C T}

Keywords

Seminiferous epithelium, Histoarchitecture, Age related changes, Mice

Article Info

Accepted:

25 April 2017

Available Online:

10 May 2017
In the present study, the histoarchitecture of seminiferous epithelium of testis in pre-pubertal and post-pubertal mice were observed. Mice belonging to the age three days post-partum to eight weeks were used. The histological observation of the testes up to six days post- partum in the present study showed that the semeniferous epithelium was made up of two distinct cell types' viz., gonocytes and sertoli cells. At day eight postpartum, both Type A and Type B spermatogonia were observed on the basement membrane of seminiferous tubules. After ten days post-partum, primary spermatocytes were observed in two to four layers next to spermatogonial layer. Both the age groups showed the presence of Leydig cells and Sertoli cells. In addition to these cellular populations, testes of post-pubertal age groups showed secondary spermatocytes, round and elongated spermatids.

\section{Introduction}

Testis is the primary organ of male reproductive system and is a bipartite glandular organ, with both exocrine and endocrine components (Siu and Cheng, 2004 and Moustafa et al., 2015). To carry out these dual roles, testicular parenchyma is composed of two compartments, a seminiferous tubular compartment and an interstitial compartment. The tubular compartment consists of an outer layer of peritubular connective tissue and an inner layer of seminiferous epithelium resting upon acellular basement membrane. The seminiferous epithelium consists of two types of cells, germ cells and sertoli cells (Ravindranath et al., 2003).

The histomorphological features of the testis, at various stages of growth and development, 
have been described in several domestic animal and avian species (Carmon and Green, 1952; Orsi et al., 1987; Sanchez et al., 1993; Wrobel, 2000; França and Godinho, 2003; Zayed and Moustafa, 1996; Kannan et al., 2015), whereas, the present study emphasised on the histomorphological changes in cellularity of seminiferous epithelium of mice.

Spermatogenesis is a continuous process in adult life due to the presence of unipotent adult stem cells, defined as the spermatogonial stem cells (SSCs) located along the basement membrane of the seminiferous tubules. SSCs were derived from gonocytes, which in turn, arose from primordial germ cells (PGCs). During embryogenesis, PGCs migrated from the yolk sac to the genital ridge. The arrival of PGCs stimulated the formation of the primitive sex cords. Once the seminiferous cords were fully formed, the PGCs were considered gonocytes (Senger, 2005). The first biologically active SSCs appeared 3 to 4 days postpartum in the male mouse (McLean et al., 2003). Spermatogenesis occurs in 35 days in mice (Treuting and Dintzis, 2012), 5-7 days after birth in rodents and 10-13 years after birth in humans (Dym et al., 2009).

The knowledge about histoarchitecture of seminiferous epithelium helps in understanding the spermatogenesis in mice. Hence, the present study was carried out in age relate changes in seminiferous epithelium of pre-pubertal and post-pubertal mice.

\section{Materials and Methods}

Testis samples were collected from eight prepubertal (0-4 weeks) and eight post-pubertal (4-8 weeks) mice. The mice were purchased from the Laboratory Animal Medicine unit, Madhavaram Milk Colony, Tamil Nadu Veterinary and Animal Sciences University,
Chennai-600 051. At the time of collection, the animals were apparently healthy and maintained in controlled environment.

Animals were euthanized by using chloroform instead of $\mathrm{CO} 2$ asphyxiation and testes were removed as per Geetha Ramesh et al., (2016). Tissue pieces were collected from testes of pre-pubertal and post-pubertal age groups and were rinsed in normal saline and fixed in 10 per cent neutral buffered formalin and Bouin's fluid. The fixed tissues were dehydrated in ascending grades of alcohol, cleared in xylene and embedded in paraffin wax (Kannan et al., 2015). Tissue sections were cut at 3-5 micron thickness in rotary microtome and used for the routine Haematoxylin-eosin staining method (Bancroft and Stevens, 2014).

\section{Results and Discussion}

In the present study, in both pre-pubertal and post-pubertal age groups, the parenchyma of the testes was composed of numerous densely packed semeniferous tubules with interstitial cells in between (Fig.1) which is in accordance with the findings of Treuting and Dintzis (2012).

\section{Pre-Pubertal}

In the pre-pubertal mice, the seminiferous epithelium was composed of gonocytes, spermatogonia, primary spermatocytes and sertoli cells. The histological observation of the testes up to six days of post partum in the present study showed that the semeniferous epithelium was made up of two distinct cell types viz., gonocytes and sertoli cells. The gonocytes were evident as large, round cells in the centre of the tubule. The cytoplasm contained a spherical nucleus dispersed with homogenous chromatin and prominent nucleolus (Fig. 2). These findings are in accordance with Bellve et al., (1977) in pre- 
pubertal mice and McLean et al., (2003) in neonatal mice.

The distribution of gonocytes at the centre of the tubule indicated that the mitosis has not been initiated in gonocytes until birth (Orth et al., 2000; McLean et al., 2003).

At day six post-partum, the gonocytes had migrated from the centre to the basement membrane of the seminiferous tubule and differentiated to form primitive type A spermatogonia. No gonocytes were visible in the centre of the tubule after day six postpartum (McLean et al., 2003). This indicated the onset of first wave of spermatogenesis in mice.

At day eight post-partum, two types of spermatogonia viz., Type A and Type B spermatogonia were observed resting upon the basement membrane. Type A spermatogonia were pale, had a reduced nuclear and cytoplasmic ratio. Nuclear chromatin was homogenous with a nucleoli. Type B spermatogonia were darker and smaller than Type A and showed an increased amount of heterochromatin (Fig.3).

At day ten post-partum, the seminiferous tubules of the testes contained primary spermatocytes. Spermatogonial cells formed a single layer and were observed to rest upon the basement membrane. Two types of spermatogonia were identified based on the appearance of the nuclear chromatin. Type A spermatogonia was pale and showed oval, intensely basophilic nucleus. Type B spermatogonia were darker and showed oval nucleus with condensed clumps of chromatin (Fig.4).

Above the spermatogonial cell layer, two to four layers of primary spermatocytes at various stages of mitotic division were observed. The primary spermatocytes were larger than the spermatogonial cell. The nucleus was round, centrally placed and basophilic in nature. It showed active chromatin.

Figure.1 Photomicrograph showing cross section of testis from pre-pubertal mouse

H\&E X 100

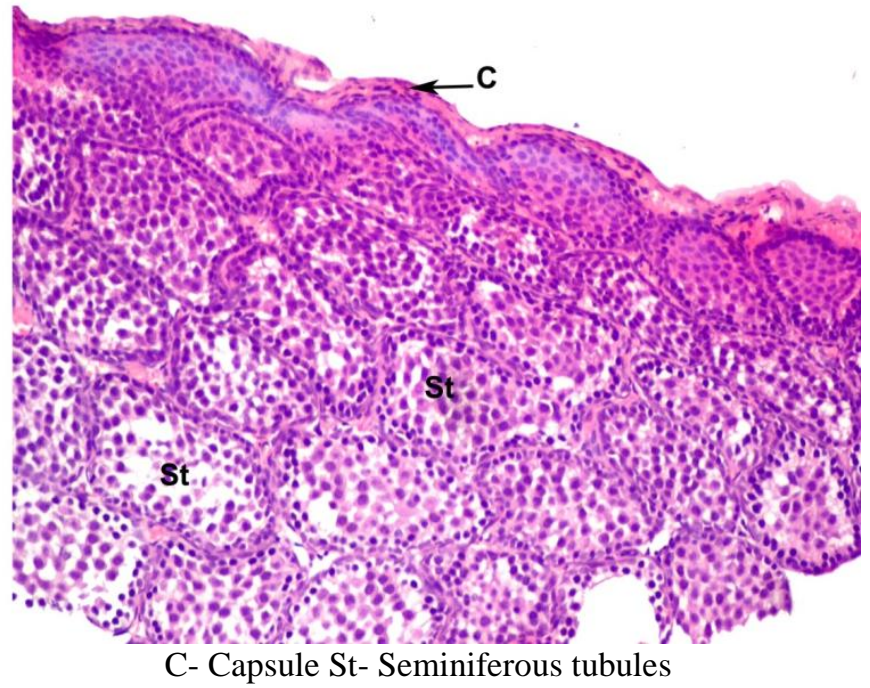


Figure.2 Photomicrograph of testis of a three day-old mice showing the cross section of seminiferous tubules with Gonocytes

$\mathrm{H} \& \mathrm{E} \times 200$

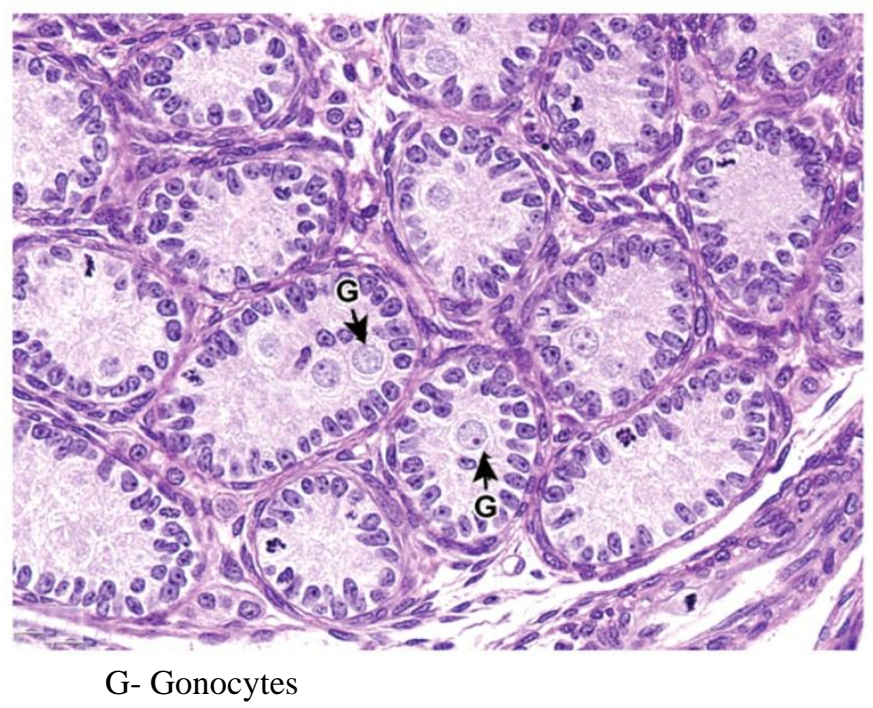

Figure.3 Photomicrograph of testis of a ten day-old mice showing the Cellular components of seminiferous epithelium

$\mathrm{H} \& \mathrm{E}$ X 400

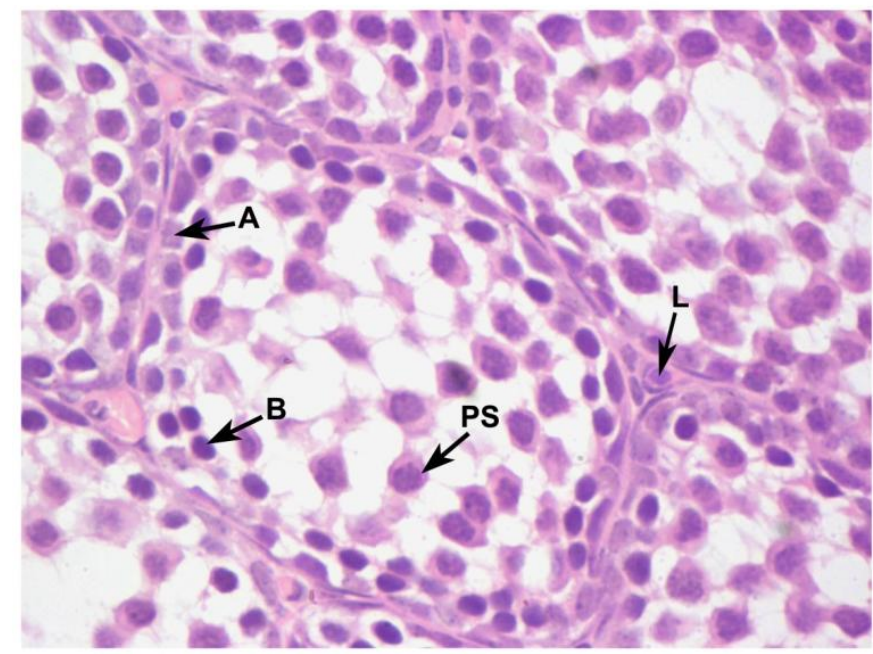

A-Type A spermatogonia,

B- Type B Spermatogonia,

L- Leydig Cell,

Ps- Primary spermatocytes 
Figure.4 Photomicrograph of testis of a ten day-old mice showing the cellular Components of seminiferous epithelium

$\mathrm{H} \& \mathrm{E} \times 1000$

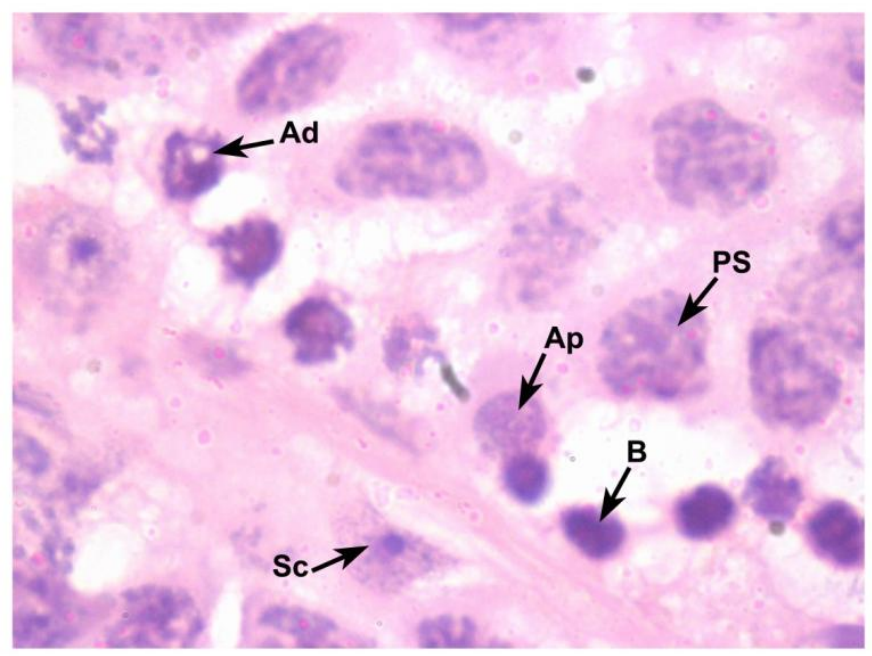

Ad- Type-A dark spermatogonia, Ap- Type A pale spermatogonia,

B- Type B spermatogonia,

PS-Primary Spermatocyte, Sc- Sertoli cell

Figure.5 Photomicrograph of testis of post-pubertal mice showing the cellular Components of seminiferous epithelium

$H \& E \times 400$

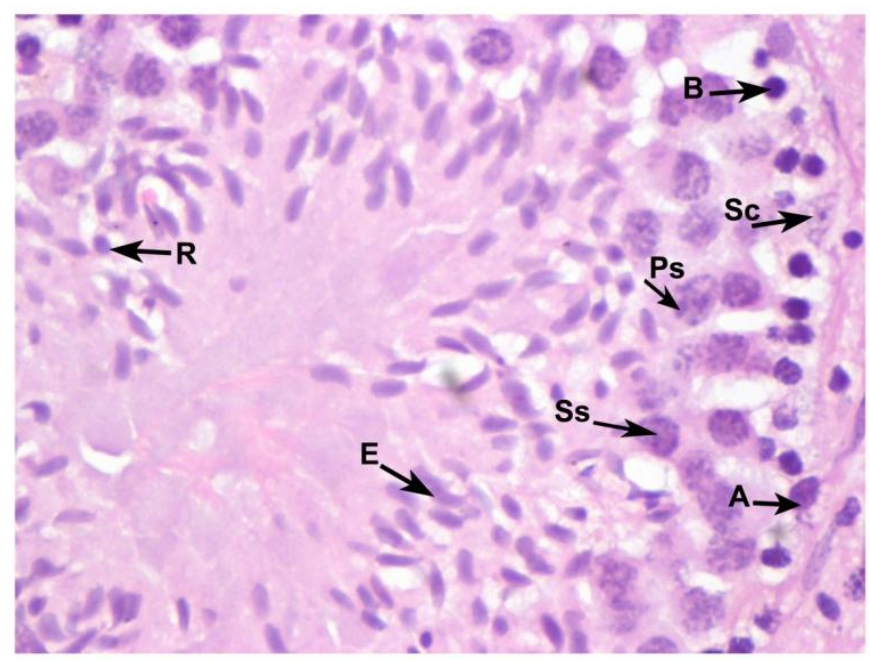

A-Type a Spermatogonia, B- Type B spermatogonia, Sc- Sertoli cell, Ps- Primary Spermatocyte, Ss- Secondary spermatocytes,

R- Round Spermatid, E- Elongated spermatid 
There were no secondary spermatocytes and spermatids observed in pre-pubertal mice. This is in contrast to the findings of Singh et al., (2015) in Wistar Rats who observed actively dividing spermatogonia, spermatocytes, round spermatids, Leydig cells and Sertoli cells from pre-pubertal age groups.

\section{Post-Pubertal}

In post-pubertal mice, the seminiferous epithelium was composed of spermatogonial cells, primary and secondary spermatocytes and spermatids. The supporting or sertoli cells were situated in between them as per de Rooij and Grootegoed (1998). Based on the appearance of nuclear chromatin, three types of spermatogonia were identified in the present study. Type a dark (Ad) spermatogonia showed oval, intensely basophilic nucleus. Type A pale (Ap) spermatogonia showed lightly stained oval nucleus whereas Type B spermatogonia showed oval nucleus with condensed clumps of chromatin (Figure 5).

The primary spermatocytes were larger than spermatogonial cells. It had a large nucleus with active chromatin which indicated the mitotic division. Singh et al., (2015) observed that the primary spermatocyte undergo first meiotic division to form the spermatids. The spermatids undergo a series of morphological and structural changes to become spermatozoa, such as formation of acrosome and tail, chromosome condensation and the removal of excessive cytoplasm at the time of spermiation.

In the present study, a concomitant increase in number of Type A and Type B spermatogonia, spermatocytes, spermatids, sertoli and leydig cells were observed in postpubertal mice when compared to pre-pubertal age group. A similar observation has been made by Singh et al., (2015) in post-pubertal Wistar rats.

The secondary spermatocytes were smaller than primary spermatocytes and the nucleus contained euchromatin. Above this layer, secondary spermatocytes, numerous round and elongated spermatids were observed in the adluminal region. The sertoli cells were larger and the nuclear cytoplasmic ratio was observed more. The nucleus was oval, located in the broader portion of the cell with small nucleoli. Numerous spermatids were seen attached to the sertoli cells (Figure 5). This finding is in accordance with the observations of Eurell and Frappier (2006) in mammalian testes.

\section{Acknowledgements}

Authors are highly thankful to the Centre for Stem Cell Research and Regenerative Medicine, Madras Veterinary College, Chennai - 600007 for providing necessary facilities to carry out the study. The authors also acknowledges the Dean, Madras Veterinary College, Chennai 600007 for providing necessary Financial support.

\section{References}

Bancroft, J.D. and A. Stevens. 2014. Theory and practice of Histological techniques, 13th Ed., Churchill Livingstone, London.

Bellve, A.R., J.C. Cavicchi, C.F. Milletfe, D.A. O'brien, Y.M. Bhatnagar and M. Dym. 1977. Spermatogenic cells of the prepuberal mouse Isolation and Morphological Characterization. J. Cell. Biol., 74: 68-85.

Brinster, R.L. 2002. Germline stem cell transplantation and transgenesis. Sci., 296: 2174-76.

Brinster, R.L. 2007. Male Germline Stem Cells: From Mice to Men. Sci., 316: 404-405.

Carmon, J.L. and W.W. Green. 1952. Histological study of the development of the testis of the ram. J. Anim Sci., 674-687. 
de Rooij, D.G. and J.A. Grootegoed, 1998. Spermatogonial stem cells. Cell Bio., 10: 694-701.

Dym, M., M. Kokkinaki and Z. He. 2009. Spermatogonial stem cells: mouse and human comparisons. Birth Defects Res., Part C, Embryo Today, 87: 27-34.

França, L.R. and Godinho, C.L. 2003. Testis morphometry, seminiferous epithelium cycle length, and daily sperm production in domestic cats (Felis catus). Biol Reprod., 68: 1554-1561.

Geetha Ramesh, T.A., Kannan, and M. Sivakumar. 2016. Age related histochemical changes in Thymus, Spleen and Mesenteric lymph nodes in Mice, Rat and Guinea pig. Int. J. Sci. Res., 5(9): 1088-1091.

Kannan, T.A., Geetha Ramesh and M. Sivakumar. 2015. Age Related Changes in the gross and histoarchitecture of Testis in Japanese Quails (Coturnix coturnix japonica). Int. J. Liv. Res., 5(6): 26-33.

McLaren, A. 1991. Development of the mammalian gonad: the fate of supporting cell lineage. BioEssays, 3: 151-156.

McLean, D.J., P.J. Friel, D.S. Johnston and M.D. Griswold. 2003. Characterization of spermatogonial stem cell maturation and differentiation in neonatal mice. Biol. Reprod., 69: 2085-2091.

Moustafa, M.N.K, R.Sayed, A.E.Zayed and Abd El -Hafeez. 2015. Morphological and Morphometric Study of the Development of Seminiferous Epithelium of Donkey (Equus asinus) from Birth to Maturity. $J$. Cytol. Histol., 6(6): 1-8.

Orsi, AM., S.M. Dias, J.E. Moreira and J.A. Camilli. 1987. Morphological development of the seminiferous epithelium of the pig at different ages (Sus scrofa of the Landrace strain). Anat. Histol. Embryol., 16: 97-102.

Orth, J.M., W.F. Jester, L.H. Li and A.L. Laslett. 2000. Gonocyte-Sertoli cell interactions during development of the neonatal rodent testis. Curr. Top. Dev. Biol,. 50: 103-124.

Ravindranath, N., L. Dettin and Martin Dym. 2003. Chapter on Mammalian Testis: Structure and Function. pp 1-19. In textbook on "Introduction to Mammalian Reproduction". Springer Publishers, New York, USA.

Sánchez, B., M. Pizarro, P. García and J.M. Flores. 1993. Postnatal development of seminiferous tubules in the cat. J. Reprod. Fertil. Suppl., 47: 343-348.

Senger, P.L. 2005. Pathways to Pregnancy and Parturition, Second Revised Edition.

Singh, M.K., N. Nair and R.S. Bedwal. 2015. Prepubertal to postpubertal development of testes in Wistar rats: a histological and morphometric study. The Egyptian J. Hist., 38(1): 116-125.

Siu, M.K. and C.Y. Cheng. 2004. Dynamic cross-talk between cells and the extracellular matrix in the testis. Bioessays, 26: 978-992.

Treuting, P.M. and S.M. Dintzis. 2012. Comparative Anatomy and Histology: A mouse and Human Atlas. p: 285-289.

Wrobel, K.H. 2000. Prespermatogenesis and spermatogoniogenesis in the bovine testis. Anat. Embryol. (Berl)., 202: 209-222.

Zayed, A.E and M.N.K. Moustafa. 1996. A histomorphological study on the testis of dog during postnatal life. Assiut. Vet. Med. J., 20: 31-46.

\section{How to cite this article:}

Kaavya, R., T.A. Kannan, Sabiha Hayath Basha, S. Vairamuthu, Geetha Ramesh and Justin William, B. 2017. Age Related Changes in the Histoarchitecture of Seminiferous Epithelium in Mice. Int.J.Curr.Microbiol.App.Sci. 6(5): 2509-2515. doi: https://doi.org/10.20546/ijcmas.2017.605.281 